\title{
A Novel Approach for Optimum Coordination of Directional Overcurrent Relays Including Far-End Faults in Interconnected Power Systems
}

\author{
Vipul N Rajput ${ }^{\# 1}$, Kartik S Pandya ${ }^{\# 2}$ \\ \# Department of Electrical Engineering, \\ Charotar University of Science and Technology, Changa-388 421, Gujarat, India \\ ${ }^{1}$ vipulrajput16986@gmail.com \\ ${ }^{2}$ kartikpandya.ee@charusat.ac.in
}

\begin{abstract}
The aim of optimum coordination of Directional Overcurrent relays (DOCRs) is to obtain optimum relay settings - Plug Setting (PS) and Time Multiplier Setting (TMS) - for minimizing the operating time of relays while adhering to various coordination and boundary constraints. In this paper, Improved Harmony Search Algorithm (IHSA) is proposed to solve relay coordination problem with three different cases on IEEE 14-bus and IEEE 30-bus systems. The first case considers only near-end fault, as reported in most literature, to demonstrate the violation in coordination constraints of Primary/Backup (P/B) relay pairs for far-end faults. In the second case, the coordination constraints for far-end faults are also included in the problem. This results in increase of operating time of primary relays. The third case presents a new formulation of objective function to reduce the operating time of relays for both near-end and far-end faults. The results obtained using IHSA are compared with Genetic Algorithm (GA), Particle Swarm Optimization (PSO) and HSA to demonstrate its effectiveness for all cases.
\end{abstract}

Keyword - Directional overcurrent relay coordination; Far-end faults; Improved harmony search algorithm; Objective function; Optimization; Power system protection

\section{INTRODUCTION}

The primary protection in distribution and sub-transmission networks and backup protection in transmission networks are usually provided using DOCRs [1]. For reducing the chances of excessive power outages, only faulted section of the power system is isolated using primary relays as quickly as possible. As long as the primary relay fails to operate, the backup relays have to instigate to clear the fault after the prescribed time interval. This practice is called relay coordination. The proper coordination of primary and backup relays is essential to ensure the reliability of protection scheme, which is achieved by locating the optimal values of PS and TMS. In modern multi-loop and multi-source interconnected power systems, finding the optimal PS and TMS using analytical methods becomes very hard. Alternatively, it can be easily solved by optimization techniques [2].

In the last few years, several optimization techniques are employed to solve the relay coordination problem. Among the conventional methods, Linear Programming (LP) technique gained good recognition to solve this problem, including simplex, two-phase simplex and dual simplex methods [3-5]. The LP methods involve assumptions in PS, allowing for operating time of each relay as a linear function of TMS. In [6, 7], Sequential Quadratic Programming (SQP) has been used in order to optimize both TMS and PS. Afterwards, Artificial Intelligence (AI) techniques are studied more to solve the coordination problem such as GA [8], modified real coded GA [9], Modified PSO (MPSO) [10, 11], Seeker Algorithm (SA) [12], group search optimization algorithm [13], chaotic firefly algorithm [14], enhanced backtracking search algorithm [15], ant colony algorithm [16], Modified adaptive teaching learning based optimization [17], etc. In [18], the comparative study of GA, PSO, Differential Evolutionary (DE), HSA and SA is presented with the same initial condition to identify the best performed method for the relay coordination. To reduce the search space and computational time, hybrid methods are also utilized for relay coordination problem, including hybrid GA-LP [1], GA-NLP [19], Biogeography-Based Optimization algorithm-LP [2], Gravitational Search Algorithm (GSA)-SQP [20] and PSO-GSA [21].

The HSA is one of the metaheuristic optimization methods which is developed by Z.W. Geem [22]. It has the characteristics of fast convergence speed, easy in concept and simple in implementation with only a few parameters and mathematical requirements $[22,23]$. Same as other metaheuristic methods, the performance of the HSA experiences a serious problem of sensitive parameters setting. Hence, fine tuning of the parameters are required, which can help the HSA to maintain a balance between diversification and intensification and to explore the population in the evolution process [24]. To improve the performance of HSA, IHSA is presented in 
[25], which updates control parameters Pitch Adjustment Rate (PAR) and bandwidth (bw) dynamically. The IHSA with improved fine-tuning and convergence rate are successfully applied to a range of applications [2629]. Due to better performance of IHSA, it is used to solve the DOCRs coordination problem in this paper.

In power systems, the operation of primary relays isolates only faulted section, whereas the operation of backup relays disconnects healthy sections along with faulted section. In majority of the literature on relay coordination, this challenge is solved by considering only near-end faults. However, a few coordination constraints for $\mathrm{P} / \mathrm{B}$ relays pairs are not satisfied for far-end faults. This sub-optimal operation of $\mathrm{P} / \mathrm{B}$ relay pairs is a foremost source of concern for protection engineers since they remove supplementary sections of power network along with faulted section which affects the reliability of the power systems. In [6,7], the DOCRs coordination problem is solved in two phases to address this issue. In the first phase, the problem is solved by normal procedure and violated coordination constraints are identified. In the second phase, only violated constraints are included in coordination problem to assure the correct operation of $\mathrm{P} / \mathrm{B}$ relay pairs in the system. However, the quality of the solution is degraded as additional constraints for far-end faults are imposed. Based on previously conducted studies, far-end fault issue is not broadly covered. Moreover, obtaining an optimal solution for relay coordination with considering far-end faults are very difficult task.

In this paper, the coordination problem is solved for near-end faults in Case-I to demonstrate the solution in terms of sub-optimal operation of $\mathrm{P} / \mathrm{B}$ relay pairs for far-end faults. To tackle this issue, all coordination constraints for near-end and far-end faults are included in Case-II. The case-III presents the novel objective function to reduce the operating time of primary relays for both near-end and far-end faults. The IHSA is used to solve the coordination problem on IEEE 14-bus and IEEE 30-bus distribution networks. To evaluate the performance of IHSA, obtained results are compared with GA, PSO and HSA.

\section{Problem formulation}

This section presents the problem formulation for relay coordination. The purpose of optimum relay coordination is to find the optimum relay settings to minimize the operating times of relays, while satisfying various coordination and boundary constraints.

\section{A. Objective function}

The most common OF presented in the literature is the minimization of total operating times of relays when they act as primary relays. This OF is expressed as:

$O F 1=\sum_{i=1}^{m} W_{i} T_{i}$

where $T_{i}$ indicates operating time of relay $R_{i}$ for fault in its primary protection zone, $m$ is the number of relays and $W_{i}$ is the coefficient representing the probability of a given fault occurring in each protection zone. It is generally set to one $[1,19]$.

\section{B. Constraints formulation}

The operating time of the relays is minimized, subject to the following constraints.

1) Relay characteristic:

The IEC standard based nonlinear and well known Inverse Definite Minimum Time (IDMT) characteristic as shown in Eq. (2), has been considered in the paper.

$$
T_{i}=\frac{0.14 \times\left(T M S_{i}\right)}{\left(I_{f, i} / P S_{i} \times C T_{i}\right)^{0.02}-1}
$$

where $I_{f, i}$ is fault current passing through relay $\mathrm{R}_{\mathrm{i}} . T M S_{i}, P S_{i}$ and $C T_{i}$ are TMS, PS and CT ratio of relay $\mathrm{R}_{\mathrm{i}}$.

Equation (2) can be written in terms of PS as follows:

$$
T_{i}=\frac{0.14 \times\left(T M S_{i}\right)}{\left(I_{c, i} / P S_{i}\right)^{0.02}-1}
$$

where $I_{c, i}=\left(I_{f, i} / C T_{i}\right)$; current through the operating coil of relay $R_{i}$. 


\section{2) Coordination Time Interval (CTI)}

The sample network of the power system is shown in Fig. 1. All relays of the network have their tripping direction away from the respected bus. The relay $R_{i}$ works as the primary relay for its near-end fault at location $F_{1}$. For the same fault, $R_{j, 1}$ and $R_{j, 2}$ provide backup protection to relay $R_{i}$.

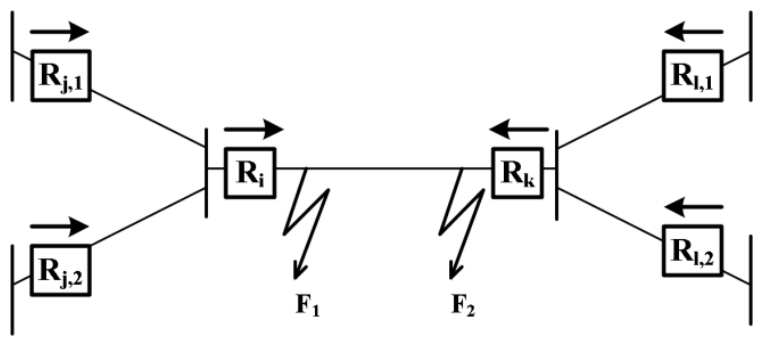

Fig. 1. Illustrative diagram for $\mathrm{P} / \mathrm{B}$ relay pair

In this case, $R_{i}$ should trip as quickly as possible, whereas $R_{j, 1}$ and $R_{j, 2}$ should operate after some prescribed time period known as CTI as expressed by Eq. (4) and Eq. (5). This time period is required for preserving selectivity between $\mathrm{P} / \mathrm{B}$ protections.

$\mathrm{T}_{\mathrm{j}, 1}^{\mathrm{F}_{1}}-T_{\mathrm{i}}^{\mathrm{F}_{1}} \geq C T I$

$\mathrm{T}_{\mathrm{j}, 2}^{\mathrm{F}_{1}}-T_{\mathrm{i}}^{\mathrm{F}_{1}} \geq C T I$

where $T_{j, 1}^{F_{1}}$ and $T_{j, 2}^{F_{1}}$ are operating time of backup relays $R_{j, 1}$ and $R_{j, 2}$ respectively, and $T_{i}^{F_{1}}$ are operating time of primary relay $\mathrm{R}_{\mathrm{i}}$ for near-end fault at $\mathrm{F}_{1}$. The CTI depends upon the types of relays, circuit breaker operating time, relay error and safety margin $[1,2,19]$. The value of CTI is generally selected between 0.2 to $0.5 \mathrm{~s}[1,2$, 19].

Similarly, the CTI constraint can be rewritten for far-end fault to $\mathrm{R}_{\mathrm{i}}$ at location $\mathrm{F}_{2}$ as follows:

$\mathrm{T}_{\mathrm{j}, 1}^{\mathrm{F}_{2}}-T_{\mathrm{i}}^{\mathrm{F}_{2}} \geq C T I$

$\mathrm{T}_{\mathrm{j}, 2}^{\mathrm{F}_{2}}-T_{\mathrm{i}}^{\mathrm{F}_{2}} \geq C T I$

where $T_{j, 1}^{F_{2}}$ and $T_{j, 2}^{F_{2}}$ are operating time of backup relays $R_{j, 1}$ and $R_{j, 2}$ respectively, and $T_{i}^{F_{2}}$ are operating time of primary relay $R_{i}$ for far-end fault at $F_{2}$. The coordination constraints for primary relay $R_{k}$ and backup relays $R_{1,1}$ and $R_{1,2}$ can be written in the same way as above for near-end and far-end faults.

\section{3) Bounds on operational time of the relay}

The relay requires a certain minimum time period to operate. Also, it is not tolerable to take extensive time for the operation. It can be stated as:

$T_{i, \min } \leq T \leq T_{i, \max }$

where $T_{i, \min }$ and $T_{i, \max }$ are minimum and maximum operationing time of relay $R_{i}$. In the practical manner, $T_{i, \min }$ depends on the relay maker, whereas $T_{i, \max }$ relies on the critical clearing time needed to avoid equipment damage as well as maintain system stability [2].

\section{4) Bounds on TMS}

The TMS adjusts the time delay before the relay trips when the fault current attains a value equal to or above the current pickup setting of the relay. It can be stated as:

$T M S_{i, \min } \leq T M S_{i} \leq T M S_{i, \max }$

where $T M S_{i, \min }$ and $T M S_{i, \max }$ are minimum and maximum value of TMS of relay $R_{i}$.

5) Bounds on PS

The relays will not malfunction under average load and small amount of overload condition. Same way, the relay must be responsive to the smallest fault current. To assure the operation of relays in this condition, the PS is decided based on the utmost load current and the smallest amount of fault current $[12,19]$.

The bound on PS of relay can be stated as:

$P S_{i, \min } \leq P S_{i} \leq P S_{i, \max }$

where $P S_{i, \min }$ and $P S_{i, \max }$ are minimum and maximum value of PS of relay $R_{i}$.

C. Proposed Objective Function (OF)

In this paper, the OF presented in [30] is modified to minimize the operating time of primary relays for both near-end and far-end faults with satisfying the coordination constraints. It is defined as: 
$O F 2=\left(\lambda_{1} \sum_{i=1}^{N_{N F}}\left(T_{i}^{N F}\right)^{2}+\lambda_{2} \sum_{i=1}^{N_{F F}}\left(T_{i}^{F F}\right)^{2}+\lambda_{3} \sum_{k=1}^{M_{N F}}\left(T_{k}^{N F}-C T I\right)^{2}+\lambda_{4} \sum_{k=1}^{M_{F F}}\left(T_{k}^{F F}-C T I\right)^{2}\right)$

where $\lambda_{1}, \lambda_{2}, \lambda_{3}$ and $\lambda_{4}$ are nonnegative weight factors. The values for both $\lambda_{1}$ and $\lambda_{2}$ are 1 , whereas $\lambda_{3}$ and $\lambda_{4}$ are 0.01. $T_{i}^{N F}$ and $T_{i}^{F F}$ are operating time of primary relays for near-end and far-end faults respectively. $T_{k}^{N F}$ and $T_{k}^{F F}$ are operating time of backup relays for near-end and far-end faults correspondingly.

\section{III.IMPROVED HARMONY SEARCH ALGORITHM}

This section illustrates the proposed improved HSA method. First, a brief overview of the HSA is provided, and then IHSA is described.

\section{A. Harmony search algorithm}

The HSA is motivated from soft computing algorithms. Probing into analogy to a musician, who reiterates the notes of a composition in search of the best harmony, in HSA the decision variables are optimized to be the best vector expressed as $O F$. The harmony search algorithm can be implemented in following steps [22, 23].

Step 1: Initialize the optimization problem and algorithm parameters:

To apply the HSA, $O F$ including constraints and decision variables can be defined as:

Minimize $\quad f(\vec{x})$

$$
\begin{array}{lll}
\text { Subject to } & g_{j}(\vec{x}) \geq 0 & (j=1,2, \ldots M), \\
& h_{l}(\vec{x})=0 & (l=1,2, \ldots P), \\
& x_{i, L} \leq x_{i} \leq x_{i, U} & (i=1,2, \ldots, N)
\end{array}
$$

where $f(\vec{x})$ is the $O F, M$ and $P$ are the number of inequality and equality constraints respectively, and $x_{i}$ is the set of decision variables with $N$ number of variables. The lower and upper limits for decision variables are $x_{i, L}$ and $x_{i, U}$ respectively. The HSA parameters (i.e. Harmony Memory Size (HMS), HMCR, PAR, and maximum number of improvisations or iterations) are also specified in this step. The Harmony Memory (HM) is the memory location where the entire solution vectors are stored. The HMCR and PAR are parameters which improve the solution vector, and these are defined in step 3.

Step 2: Initialize the HM:

In this step, The $H M$ matrix shown in Eq. (13) is filled up by randomly generated solution vectors $\left(x^{1}, \ldots \ldots, x^{H M S}\right)$ as the HMS.

$$
H M=\left[\begin{array}{ccc}
x_{1}^{1} & \cdots & x_{N}^{1} \\
\vdots & \ddots & \vdots \\
x_{1}^{H M S} & \cdots & x_{N}^{H M S}
\end{array}\right]
$$

There is a chance of infeasible solutions in which constraints are violated. However the algorithm enforces the search towards a feasible solution region. The static penalty function is used to handle the constraints, and it can be expressed as:

$$
\begin{gathered}
\text { fitness }(\vec{x})=f(\vec{x})+\sum_{j=1}^{M} \alpha_{j} \times \min \left[0, g_{j}(\vec{x})\right]^{2}+\sum_{l=1}^{P} \beta_{l} \times \min \left[0, h_{l}(\vec{x})\right]^{2} \\
g_{j}(\vec{x})=\left\{\begin{array}{cc}
\text { if } x_{i, L} \leq x \leq x_{i, U} \\
\left(x-x_{i, U}\right)^{2} & \text { if } x>x_{i, U} \\
\left(x_{i, L}-x\right)^{2} & \text { if } x<x_{i, L}
\end{array}\right.
\end{gathered}
$$

where $\alpha_{j}$ and $\beta_{l}$ are the penalty coefficient equal to 1000 .

\section{Step 3: Improvise a new harmony:}

A new harmony vector $\vec{x}=\left(x_{1}^{\prime}, x_{2}^{\prime}, \ldots, x_{N}^{\prime}\right)$ is produced based on the memory consideration, pitch adjustment and random selection. The new harmony generation is called improvisation. According to memory consideration, $i^{\text {th }}$ variable $x_{i}^{1}=\left(x_{L}^{1}-x_{H M S}^{1}\right)$. The HMCR is defined as the probability of choosing a value from the historical values stored in the HM, and (1-HMCR) is the probability of producing a component at random from the achievable range of values, as shown in Eq. (16). The HMCR varies between 0 and 1.

$$
x_{i, \text { new }}^{\prime} \leftarrow\left\{\begin{array}{l}
x_{i}^{\prime} \in\left\{x_{i}^{1}, x_{i}^{2}, \ldots, x_{i}^{H M S}\right\} \text { with probability } H M C R \\
x_{i}^{\prime} \in X_{i}^{\prime} \text { with probability }(1-H M C R)
\end{array}\right.
$$


If $x_{i}^{\prime}$ is produced from the HM, further it is adjusted according to PAR. The PAR settles on the probability of an elements from the $H M$ mutating and $(1-P A R)$ is the probability of no mutation. The pitch adjustment for the particular $x_{i}^{\prime}$ is expressed as:

$$
x_{i, n e w}^{\prime} \leftarrow\left\{\begin{array}{c}
x_{i}^{\prime} \pm \text { rand }[0,1] \times \text { bw with probibility } P A R \\
x_{i}^{\prime} \text { with probability }(1-P A R)
\end{array}\right.
$$

where $\operatorname{rand}[0,1]$ is the randomly generated value between 0 and 1 and $b w$ is the arbitrary distance bandwidth for the continuous design variable.

Step 4: Update the HM:

If $x^{\prime}$ is better than the worst vector $x^{\text {worst }}$ in the HM in terms of the OF value, replace $x^{\text {worst }}$ with $x^{\prime}$.

\section{Step 5: Check stopping criterion:}

Repeat step 3 and step 4 until stopping criterion (e.g. maximum numbers of improvisations) has been satisfied which is explained as follows:

$$
\Delta f=f^{k}-f^{k-1} \leq \varepsilon
$$

where $\Delta f=$ difference of the best fitness value of two consecutive iterations.

And,

$$
\Delta x=x^{k}-x^{k-1} \leq \varepsilon
$$

where $\Delta x=$ difference of the best values of control variables in two consecutive iterations.

$$
\Delta x^{T} \cdot \Delta x \leq \varepsilon
$$

where $\varepsilon$ (Best error value $)=10^{-5}$

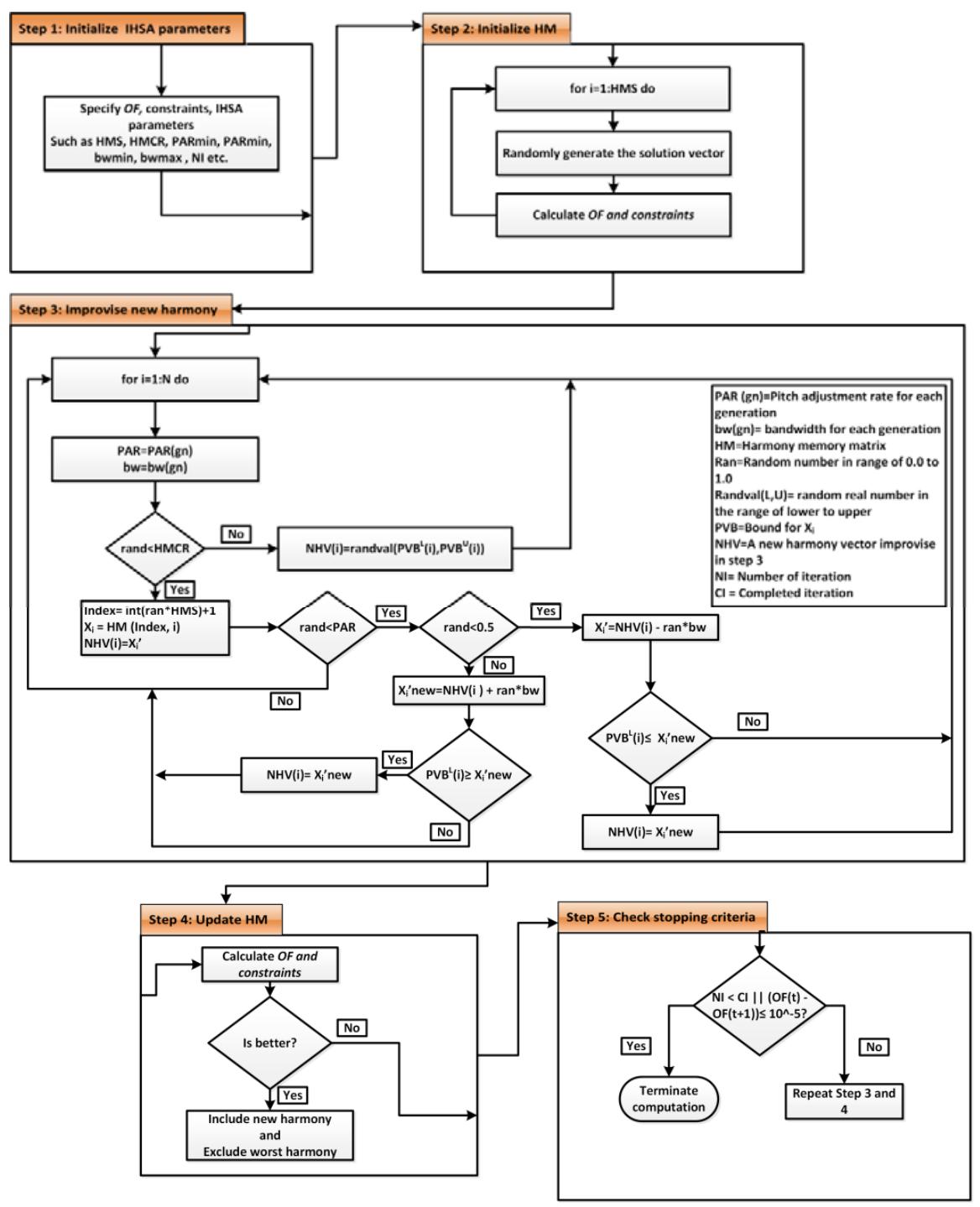

Fig. 2. Flowchart for the IHSA [25] 
If $\Delta f$ and $\Delta x$ are very small (i.e. $10^{-5}$ ), then it confirms that there is no significant improvement in the value of an optimal solution and no further iterations are required. Therefore, the HSA is terminated immediately whenever the best error value found by HSA drops below the desired threshold (i.e.10 $0^{-5}$ ) or the numbers of iterations (Maximum iterations) assure the termination criteria.

\section{B. Improved harmony search algorithm}

In the HSA, PAR and $b w$ introduced in Step 3 of the HSA are vital parameters in fine-tuning of solution vectors, and can be very helpful in the adjustment of the algorithm convergence rate for an optimal solution. As explained in Step 1 of the HSA, entire parameters are initialized and cannot be changed during new generation. In [25], HSA is improved to overcome the limitations associated with fixed values of $P A R$ and $b w$. In the IHSA, $P A R$ and $b w$ values have been dynamically adjusted in the improvisation process of Step 3 of the HSA. The value of $P A R$ is linearly increased in each iteration as expressed below:

$P A R_{(g n)}=P A R_{\text {min }}+\frac{\left(P A R_{\text {max }}-P A R_{\text {min }}\right)}{N I} \times g n$

where $P A R_{(g n)}$ is the pitch adjusting rate for each generation, $P A R_{\min }$ and $P A R_{\max }$ are the minimum and maximum pitch adjusting rate respectively, $g n$ is the generation number and $N I$ is the maximum number of iterations.

The value of $b w$ is exponentially decreased in each iteration as expressed by following equation:

$b w_{(g n)}=b w_{\text {max }} \exp \left(\frac{\ln \left(\frac{b w_{\min }}{b w_{\max }}\right)}{N I} \times g n\right)$

where $b w_{(g n)}$ is the bandwidth for each generation, $b w_{\min }$ and $b w_{\max }$ are the minimum and maximum bandwidth respectively. The optimization procedure for the IHSA is shown in Fig. 2.

\section{IV.RESULTS AND DISCUSSION}

In this paper, DOCRs coordination problem is formulated with three cases; Case-I: by considering coordination constraints only for near-end faults, Case-II: by considering coordination constraints for both nearend and far-end faults, and Case-III: with a new formulation of the OF. The IHSA is used to solve the relay coordination problem on the distribution network of the IEEE 14-bus and IEEE 30-bus systems. In each case, the obtained results are compared with the GA, PSO and HSA. The directional IDMT relays are considered in all test systems. The range of TMS value is considered from 0.1 to 1.1 and the range of PS is considered from 0.5 to 2.5. Both the CTI of P/B relay pairs and minimum operating time are assumed to be $0.2 \mathrm{~s}$ in all cases. The simulations are carried out using MATLAB version 7.8.0.347 (R2009a) on a Windows Vista platform with 2 GB RAM and an Intel Core 2 Duo processor clocked at $2 \mathrm{GHz}$.

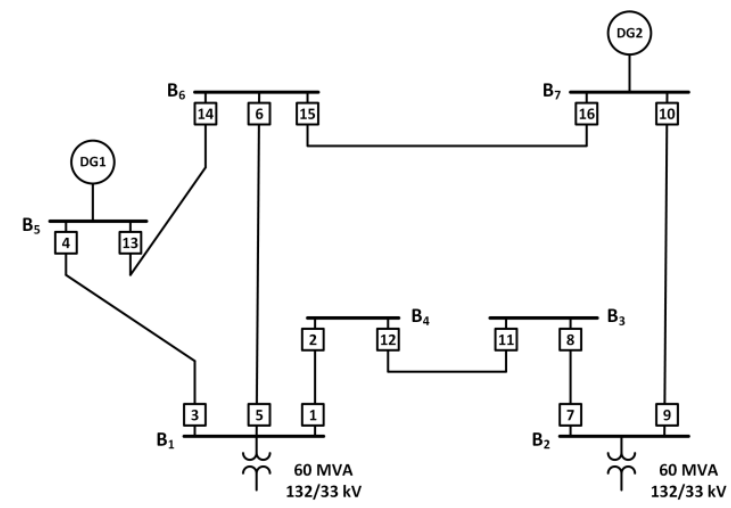

Fig. 3. Single line diagram of IEEE 14-bus distribution network

\section{A. Test system 1: IEEE 14-bus network}

The single line diagram of a modified distribution network of IEEE 14-bus network is shown Fig. 3. This meshed distribution network is supplied through two distribution transformers with $10 \%$ transient reactance connected at buses $B_{1}$ and $B_{2}$. The system has a total of 16 DOCRs installed at each end of the line. The system data are given in $[31,32]$. Based on the system, DGs are assumed to be connected at buses $\mathrm{B}_{5}$ and $\mathrm{B}_{7}$. The selected DGs are synchronous type with a rating of 5 MVA, operating nominally at 0.9 lagging power factor $[31,32]$. The ratio of current transformer of relays $(1,2,3,5,7,8,9,10),(11,12,15,16)$ and $(4,6,13,14)$ is assumed as 120:1, 80:1 and 40:1 respectively. The 3- $\Phi$ short circuit results for near-end and far-end faults are presented in Table I. 


\section{1) Case-I}

In this case, only near-end faults are considered in relay coordination problem as stated in the majority of the literature. The OF1 given by Eq. (1) are formulated together with the characteristic of relays given by Eq. (3), coordination constraints for near-end faults given by Eqs. (4) and (5), operating time constraints given by Eq. (8), and bounds on relay settings given by Eqs. (9) and (10). By implementing IHSA, the obtained results of relay settings and operating times of primary relays are given in Table II. The obtained CTI values for P/B relay pairs are given in Table III.

TABLE I. 3- $\Phi$ short circuit results of near-end and far-end faults for IEEE 14-bus network

\begin{tabular}{|c|c|c|c|c|c|c|c|c|c|c|c|}
\hline \multirow{2}{*}{$\begin{array}{c}\text { Primary } \\
\text { Relay } \\
\text { (PR) }\end{array}$} & \multirow{2}{*}{$\begin{array}{c}\text { Backup } \\
\text { Relay } \\
\text { (BR) }\end{array}$} & \multicolumn{2}{|c|}{$\begin{array}{l}\text { Near-end Fault } \\
\text { (NF) }\end{array}$} & \multicolumn{2}{|c|}{$\begin{array}{l}\text { Far-end Fault } \\
\text { (FF) }\end{array}$} & \multirow{2}{*}{$\begin{array}{c}\text { Primary } \\
\text { Relay } \\
\text { (PR) }\end{array}$} & \multirow{2}{*}{$\begin{array}{c}\text { Backup } \\
\text { Relay } \\
\text { (BR) }\end{array}$} & \multicolumn{2}{|c|}{$\begin{array}{l}\text { Near-end Fault } \\
\text { (NF) }\end{array}$} & \multicolumn{2}{|c|}{$\begin{array}{l}\text { Far-end Fault } \\
\text { (FF) }\end{array}$} \\
\hline & & PR & BR & PR & BR & & & PR & BR & PR & BR \\
\hline 1 & 4 & 4952 & 404 & 2804 & 173 & 8 & 12 & 1820 & 1820 & 1454 & 1454 \\
\hline 1 & 6 & 4952 & 928 & 2804 & 221 & 9 & 8 & 5070 & 1470 & 2463 & 293 \\
\hline 2 & 11 & 2318 & 2318 & 1426 & 1426 & 10 & 15 & 2147 & 1784 & 1151 & 857 \\
\hline 3 & 2 & 5968 & 1420 & 2280 & 822 & 11 & 7 & 3689 & 3689 & 2318 & 2318 \\
\hline 3 & 6 & 5968 & 928 & ---- & ---- & 12 & 1 & 2804 & 2804 & 1740 & 1740 \\
\hline 4 & 14 & 2140 & 1777 & 407 & 66 & 13 & 3 & 2683 & 2320 & 924 & 614 \\
\hline 5 & 2 & 5444 & 1420 & 2989 & 823 & 14 & 5 & 4370 & 2989 & 1799 & 902 \\
\hline 5 & 4 & 5444 & 404 & ---- & ---- & 14 & 16 & 4370 & 1370 & 1799 & 897 \\
\hline 6 & 13 & 2294 & 924 & ---- & ---- & 15 & 5 & 3913 & 2989 & 1784 & 1340 \\
\hline 6 & 16 & 2294 & 1370 & 924 & 994 & 15 & 13 & 3913 & 924 & 1784 & 444 \\
\hline 7 & 10 & 4770 & 1150 & 3689 & 729 & 16 & 9 & 2826 & 2463 & 1365 & 1107 \\
\hline
\end{tabular}

TABLE II. Results for IEEE 14-bus network

\begin{tabular}{cccccccccccccc}
\hline \multirow{2}{*}{ Relay no. } & \multicolumn{4}{c}{ Case-I } & \multicolumn{1}{c}{ Case-II } & \multicolumn{4}{c}{ Case-III } \\
& $\mathbf{P S}$ & $\mathbf{T M S}$ & $\mathbf{T}_{\mathbf{i}}^{\mathbf{N F}}(\mathbf{s})$ & $\mathbf{T}_{\mathbf{i}}^{\mathbf{F F}}(\mathbf{s})$ & $\mathbf{P S}$ & $\mathbf{T M S}$ & $\mathbf{T}_{\mathbf{i}}^{\mathbf{N F}}(\mathbf{s})$ & $\mathbf{T}_{\mathbf{i}}^{\mathbf{F F}}(\mathbf{s})$ & $\mathbf{P S}$ & $\mathbf{T M S}$ & $\mathbf{T}_{\mathbf{i}}^{\mathbf{N F}}(\mathbf{s})$ & $\mathbf{T}_{\mathbf{i}}^{\mathbf{F F}}(\mathbf{s})$ \\
\hline 1 & 1.641 & 0.440 & 0.924 & 1.129 & 2.063 & 0.383 & 0.867 & 1.077 & 2.500 & 0.340 & 0.824 & 1.040 \\
2 & 1.848 & 0.272 & 0.791 & 1.003 & 1.247 & 0.330 & 0.821 & 1.003 & 2.500 & 0.198 & 0.663 & 0.874 \\
3 & 2.364 & 0.268 & 0.597 & 0.882 & 1.260 & 0.373 & 0.684 & 0.936 & 2.500 & 0.244 & 0.553 & 0.824 \\
4 & 1.794 & 0.282 & 0.563 & 1.120 & 1.159 & 0.337 & 0.593 & 1.064 & 2.500 & 0.207 & 0.459 & 1.019 \\
5 & 0.864 & 0.474 & 0.805 & 0.954 & 1.561 & 0.400 & 0.804 & 0.984 & 2.500 & 0.288 & 0.677 & 0.858 \\
6 & 2.201 & 0.387 & 0.805 & 1.125 & 1.726 & 0.407 & 0.785 & 1.069 & 2.500 & 0.333 & 0.722 & 1.026 \\
7 & 1.896 & 0.429 & 0.958 & 1.049 & 1.747 & 0.459 & 0.996 & 1.088 & 2.500 & 0.339 & 0.834 & 0.922 \\
8 & 2.105 & 0.249 & 0.867 & 0.980 & 1.573 & 0.276 & 0.834 & 0.928 & 1.428 & 0.280 & 0.809 & 0.896 \\
9 & 1.029 & 0.426 & 0.774 & 0.968 & 2.341 & 0.307 & 0.723 & 0.970 & 2.500 & 0.287 & 0.691 & 0.935 \\
10 & 2.125 & 0.253 & 0.813 & 1.157 & 2.214 & 0.254 & 0.834 & 1.196 & 2.500 & 0.201 & 0.702 & 1.034 \\
11 & 1.647 & 0.418 & 0.849 & 0.991 & 1.202 & 0.479 & 0.887 & 1.021 & 2.500 & 0.310 & 0.722 & 0.863 \\
12 & 1.123 & 0.473 & 0.929 & 1.084 & 1.938 & 0.373 & 0.876 & 1.054 & 2.500 & 0.325 & 0.840 & 1.030 \\
13 & 2.450 & 0.329 & 0.674 & 1.005 & 0.972 & 0.460 & 0.729 & 0.985 & 2.5000 & 0.299 & 0.616 & 0.922 \\
14 & 0.704 & 0.476 & 0.628 & 0.769 & 0.535 & 0.535 & 0.668 & 0.808 & 0.5000 & 0.442 & 0.544 & 0.657 \\
15 & 2.11 & 0.349 & 0.754 & 1.013 & 1.747 & 0.386 & 0.784 & 1.034 & 2.500 & 0.288 & 0.658 & 0.902 \\
16 & 1.530 & 0.355 & 0.768 & 1.007 & 2.380 & 0.305 & 0.770 & 1.062 & 2.500 & 0.285 & 0.735 & 1.020 \\
\hline
\end{tabular}

\begin{tabular}{|c|c|c|c|}
\hline$\sum_{i=1}^{N_{N F}} T_{i}^{N F}$ & $12.499 \mathrm{~s}$ & $12.654 \mathrm{~s}$ & $11.050 \mathrm{~s}$ \\
\hline$\sum_{i=1}^{N_{F F}} T_{i}^{F F}$ & $16.234 \mathrm{~s}$ & $16.278 \mathrm{~s}$ & $14.822 \mathrm{~s}$ \\
\hline
\end{tabular}

As clearly seen, in Table III, entire coordination constraints are satisfied for near-end faults. When these obtained settings of relays are tested for coordination constraints of far-end faults given by Eqs. (6) and (7), the constraints of CTI for P/B relay pairs 6-16 and 8-12 are violated, which are highlighted in Table III. From the results obtained for the Case-I, the backup relays are operated earlier than defined operating time of primary relays for far-end faults. Therefore, it can be said that the feasible solution cannot be achieved for relay coordination by considering only near-end fault.

\section{2) Case-II}

In this case, the coordination constraints for far-end faults, expressed by Eqs. (6) and (7), are included in the relay coordination problem. The obtained results of relay settings and operating times of primary relays are 
given in Table II, whereas obtained CTI for P/B relays pairs are given in Table III. As shown in Table II, the obtained total operating time of primary relays for near-end and far-end faults are correspondingly $0.155 \mathrm{~s}$ and $0.044 \mathrm{~s}$ higher in Case-II compared to Case-I due to the inclusion of additional constraints for far-end faults. On the other hand, the entire coordination constraints for near-end and far-end faults are satisfied.

TABLE III. CTI of P/B relay pairs for IEEE 14-bus network

\begin{tabular}{|c|c|c|c|c|c|c|c|}
\hline \multirow{3}{*}{ PR } & \multirow{3}{*}{ BR } & \multicolumn{6}{|c|}{ CTI (s) } \\
\hline & & \multicolumn{2}{|c|}{ Case-I } & \multicolumn{2}{|c|}{ Case-II } & \multicolumn{2}{|c|}{ Case-III } \\
\hline & & NF & FF & NF & FF & NF & FF \\
\hline 1 & 4 & 0.200 & 1.099 & 0.200 & 0.693 & 0.200 & 1.591 \\
\hline 1 & 6 & 0.200 & 1.791 & 0.200 & 1.342 & 0.200 & 1.879 \\
\hline 2 & 11 & 0.200 & 0.200 & 0.200 & 0.208 & 0.200 & 0.208 \\
\hline 3 & 2 & 0.408 & 0.551 & 0.320 & 0.398 & 0.324 & 0.536 \\
\hline 3 & 6 & 0.527 & --- & 0.383 & --- & 0.471 & --- \\
\hline 4 & 14 & 0.208 & 2.757 & 0.218 & 2.224 & 0.200 & 1.542 \\
\hline 5 & 2 & 0.200 & 0.477 & 0.200 & 0.349 & 0.200 & 0.500 \\
\hline 5 & 4 & 0.320 & ---- & 0.263 & --- & 0.347 & ---- \\
\hline 6 & 13 & 0.200 & ---- & 0.200 & ---- & 0.200 & ---- \\
\hline 6 & 16 & 0.200 & 0.038 & 0.275 & 0.200 & 0.297 & 0.200 \\
\hline 7 & 10 & 0.200 & 0.619 & 0.201 & 0.657 & 0.200 & 0.650 \\
\hline 8 & 12 & 0.200 & 0.175 & 0.200 & 0.213 & 0.200 & 0.230 \\
\hline 9 & 8 & 0.200 & 10.789 & 0.201 & 3.407 & 0.200 & 2.692 \\
\hline 10 & 15 & 0.200 & 0.325 & 0.201 & 0.268 & 0.200 & 0.333 \\
\hline 11 & 7 & 0.200 & 0.274 & 0.201 & 0.283 & 0.200 & 0.274 \\
\hline 12 & 1 & 0.200 & 0.299 & 0.200 & 0.292 & 0.200 & 0.298 \\
\hline 13 & 3 & 0.200 & 1.405 & 0.201 & 0.852 & 0.200 & 1.441 \\
\hline 14 & 5 & 0.327 & 0.732 & 0.317 & 0.947 & 0.314 & 1.157 \\
\hline 14 & 16 & 0.377 & 0.455 & 0.392 & 0.547 & 0.475 & 0.654 \\
\hline 15 & 5 & 0.200 & 0.250 & 0.200 & 0.363 & 0.200 & 0.427 \\
\hline 15 & 13 & 0.251 & 0.490 & 0.200 & 0.256 & 0.263 & 0.483 \\
\hline 16 & 9 & 0.200 & 0.325 & 0.200 & 0.486 & 0.200 & 0.499 \\
\hline
\end{tabular}

Bold digits indicate violation in CTI of P/B relay pairs

\section{3) Case-III}

As explained in case-I, the mis-coordination in a few P/B relay pairs for far-end faults are observed when only near-end faults is considered in coordination problem. While including the far-end faults in the problem as described in Case-II, all the coordination constraints are satisfied. But, the total operating time of relays is increased. To overcome these problems, the relay coordination problem is formulated using the OF2 expressed by Eq. (11) in case-III.

TABLE IV. Performance analysis for IEEE 14-bus network for 50 simulations

\begin{tabular}{|c|c|c|c|c|c|c|c|c|}
\hline \multirow[t]{2}{*}{ Cases } & \multirow[t]{2}{*}{ Algorithm } & \multicolumn{4}{|c|}{$\sum_{i=1}^{N_{N F}} T_{i}^{N F}$} & \multirow{2}{*}{$\begin{array}{c}\text { Violated } \\
\text { cases }\end{array}$} & \multirow{2}{*}{$\begin{array}{c}\text { Number } \\
\text { of } \\
\text { iterations }\end{array}$} & \multirow{2}{*}{$\begin{array}{c}\text { Mean } \\
\text { convergence } \\
\text { time (s) }\end{array}$} \\
\hline & & $\begin{array}{c}\text { Best } \\
\text { value }\end{array}$ & $\begin{array}{l}\text { Worst } \\
\text { value }\end{array}$ & $\begin{array}{l}\text { Mean } \\
\text { value }\end{array}$ & $\begin{array}{l}\text { Standard } \\
\text { deviation }\end{array}$ & & & \\
\hline \multirow{4}{*}{ Case-I } & GA & 19.13 & 22.61 & 20.91 & 1.04 & 3 & 368 & 76 \\
\hline & PSO & 16.77 & 19.45 & 18.43 & 0.81 & 2 & 332 & 70 \\
\hline & HSA & 14.27 & 15.55 & 14.93 & 0.51 & 2 & 302 & 62 \\
\hline & IHSA & 12.50 & 13.22 & 12.45 & 0.23 & 2 & 193 & 41 \\
\hline \multirow{4}{*}{ Case-II } & GA & 21.98 & 25.95 & 23.42 & 1.23 & 2 & 517 & 106 \\
\hline & PSO & 17.69 & 20.56 & 19.45 & 0.88 & 1 & 446 & 93 \\
\hline & HSA & 15.06 & 16.76 & 15.98 & 0.64 & 0 & 401 & 80 \\
\hline & IHSA & 12.65 & 13.39 & 13.10 & 0.26 & 0 & 278 & 55 \\
\hline \multirow{4}{*}{ Case-III } & GA & 18.57 & 20.80 & 19.88 & 0.98 & 0 & 412 & 91 \\
\hline & PSO & 15.44 & 16.86 & 16.73 & 0.71 & 0 & 352 & 79 \\
\hline & HSA & 13.76 & 14.78 & 14.16 & 0.43 & 0 & 305 & 68 \\
\hline & IHSA & 11.05 & 11.68 & 11.32 & 0.21 & 0 & 213 & 43 \\
\hline
\end{tabular}

The obtained results of relay settings and operating time of primary relays for near-end and far-end faults are tabulated in Table II. The results show that the total operating time of primary relays for near-end faults are $1.449 \mathrm{~s}$ and $1.604 \mathrm{~s}$ less than Case-I and Case-II respectively. Similarly, the total operating time of primary relays for far-end faults are $1.412 \mathrm{~s}$ and $1.456 \mathrm{~s}$ less than Case-I and Case-II respectively. The CTI values for 
$\mathrm{P} / \mathrm{B}$ relay pairs are shown in Table III. It is clearly seen from Table III that the coordination constraints for both near-end and far-end faults are also satisfied in this case.

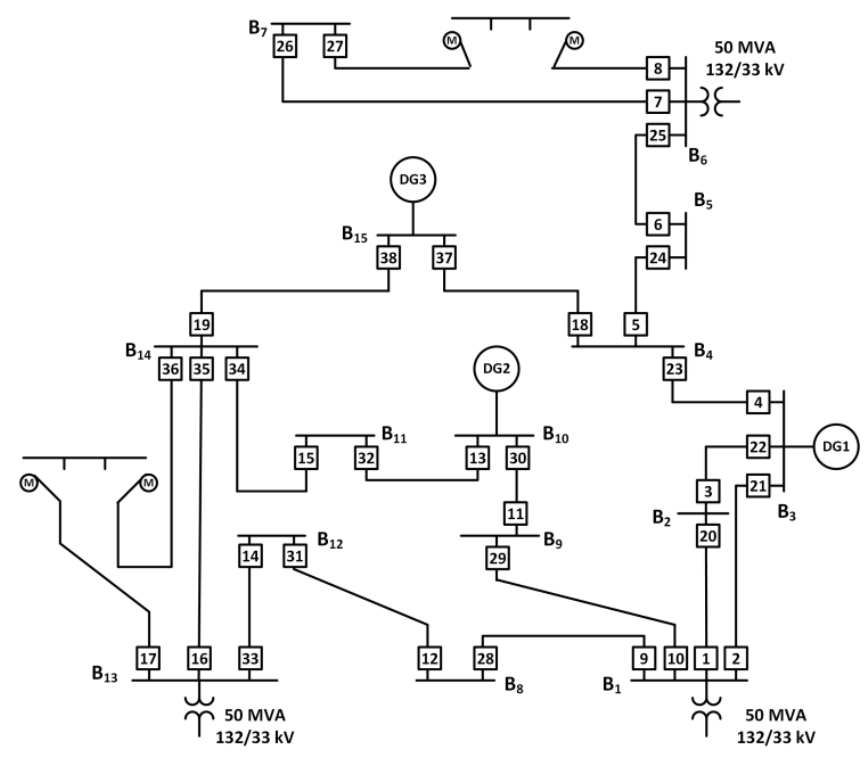

Fig. 4. Single line diagram of IEEE 30-bus distribution network

TABLE V. 3-Ф short circuit results of near-end and far-end faults for IEEE 30-bus network

\begin{tabular}{|c|c|c|c|c|c|c|c|c|c|c|c|}
\hline \multirow{3}{*}{ PR } & \multirow{3}{*}{ BR } & \multicolumn{4}{|c|}{ Fault current (A) } & \multirow{3}{*}{ PR } & \multirow{3}{*}{ BR } & \multicolumn{4}{|c|}{ Fault current (A) } \\
\hline & & \multicolumn{2}{|c|}{ NF } & \multicolumn{2}{|c|}{ FF } & & & \multicolumn{2}{|c|}{ NF } & \multicolumn{2}{|c|}{ FF } \\
\hline & & PR & BR & PR & BR & & & PR & BR & PR & BR \\
\hline 1 & 21 & 5794 & 811 & ----- & ----- & 19 & 16 & 4263 & 2430 & 2468 & 1490 \\
\hline 1 & 28 & 5794 & 1230 & 3102 & 975 & 19 & 17 & 4263 & 623 & 2468 & 382 \\
\hline 1 & 29 & 5794 & 973 & 3102 & 757 & 20 & 22 & 3328 & 3328 & 1240 & 1240 \\
\hline 2 & 20 & 6223 & 1240 & ----- & ---- & 21 & 3 & 4909 & 2440 & ---- & ---- \\
\hline 2 & 28 & 6223 & 1230 & 1605 & 941 & 21 & 23 & 4909 & 1830 & 811 & 1470 \\
\hline 2 & 29 & 6223 & 973 & 1605 & 724 & 22 & 2 & 4069 & 1600 & 3328 & 1020 \\
\hline 3 & 1 & 3102 & 3102 & 2440 & 2440 & 22 & 23 & 4069 & 1830 & 3328 & 1700 \\
\hline 4 & 2 & 4679 & 1600 & 2678 & 882 & 23 & 24 & 3070 & 1440 & 1838 & 1140 \\
\hline 4 & 3 & 4679 & 2440 & 2678 & 1350 & 23 & 37 & 3070 & 1630 & 1838 & 698 \\
\hline 5 & 4 & 4306 & 2678 & 2251 & 1400 & 24 & 25 & 2060 & 2060 & 1440 & 1440 \\
\hline 5 & 37 & 4306 & 1628 & 2251 & 851 & 25 & ----- & 2780 & ------ & 2060 & ------ \\
\hline 6 & 5 & 2251 & 2251 & 1724 & 1724 & 26 & 8 & 946 & 946 & ------ & ------ \\
\hline 7 & 6 & 4510 & 1730 & 1310 & 866 & 27 & 7 & 1310 & 1310 & 683 & 683 \\
\hline 8 & 6 & 4510 & 1730 & 1777 & 943 & 28 & 31 & 1649 & 1649 & 1222 & 1222 \\
\hline 9 & 20 & 5804 & 1240 & 4233 & 893 & 29 & 30 & 1897 & 1897 & 973 & 973 \\
\hline 9 & 21 & 5804 & 811 & 4233 & 584 & 30 & 32 & 2237 & 1860 & 1897 & 1550 \\
\hline 9 & 29 & 5804 & 973 & 4233 & 576 & 31 & 33 & 2666 & 2666 & 1649 & 1649 \\
\hline 10 & 20 & 6061 & 1240 & 3038 & 589 & 32 & 34 & 2510 & 2510 & 1864 & 1864 \\
\hline 10 & 21 & 6061 & 811 & 3038 & 385 & 33 & 35 & 4866 & 1660 & 2666 & 626 \\
\hline 10 & 28 & 6061 & 1230 & 3038 & 354 & 33 & 36 & 4866 & 426 & 2666 & 160 \\
\hline 11 & 10 & 3038 & 3038 & 2555 & 2555 & 34 & 16 & 4693 & 2430 & 2520 & 1340 \\
\hline 12 & 9 & 4233 & 4233 & 2556 & 2556 & 34 & 17 & 4693 & 623 & 2520 & 342 \\
\hline 13 & 11 & 2927 & 2550 & 2142 & 1830 & 34 & 38 & 4693 & 1640 & 2520 & 838 \\
\hline 14 & 12 & 2556 & 2556 & 1452 & 1452 & 35 & 15 & 3473 & 1210 & 1653 & 829 \\
\hline 15 & 13 & 2142 & 2142 & 1216 & 1216 & 35 & 17 & 3473 & 623 & ------ & ----- \\
\hline 16 & 14 & 4656 & 1450 & 2425 & 798 & 35 & 38 & 3473 & 1640 & 1653 & 1250 \\
\hline 16 & 36 & 4656 & 426 & ----- & ----- & 36 & 15 & 5280 & 1210 & 2128 & 741 \\
\hline 17 & 14 & 5890 & 1450 & 2268 & 805 & 36 & 16 & 5280 & 2430 & 2128 & 337 \\
\hline 17 & 35 & 5890 & 1660 & ------ & ----- & 36 & 38 & 5280 & 1640 & 2128 & 1050 \\
\hline 18 & 4 & 4120 & 2680 & 2055 & 1110 & 37 & 19 & 3099 & 2460 & 1628 & 1160 \\
\hline 18 & 24 & 4120 & 1440 & 2055 & 945 & 38 & 18 & 2689 & 2050 & 1638 & 1130 \\
\hline 19 & 15 & 4263 & 1210 & 2468 & 596 & & & & --- & & \\
\hline
\end{tabular}

Further, to evaluate the effectiveness, performance of the proposed method is compared with GA, PSO and HSA as shown in Table IV. The GA parameters as Population Size $\left(\mathrm{P}_{\mathrm{s}}\right)=150$, Crossover Rate $(\mathrm{CR})=0.8$, Mutation Rate $(\mathrm{MR})=0.1$, PSO parameters as numbers of particles $(\mathrm{N})=30$, acceleration coefficients $\left(\mathrm{C}_{1}, \mathrm{C}_{2}\right)=$ 
$(2.1,2.0)$, minimum and maximum inertia weights $\left(\mathrm{w}_{\min }, \mathrm{w}_{\max }\right)=(0.2,1.0)$, minimum and maximum velocity of particles $\left(\mathrm{v}_{\min }, \mathrm{v}_{\max }\right)=(-0.45,0.45)$, IHSA parameters as HMS $=30, \mathrm{HMCR}=0.9, \mathrm{PAR}=0.3, \mathrm{bw}=0.01$, IHSA parameters as HMS $=15, \mathrm{HMCR}=0.99,\left(\mathrm{PAR}_{\min }, \mathrm{PAR}_{\max }\right)=(0.3,0.7)$ and $\left(\mathrm{bw}_{\min }, \mathrm{bw}_{\max }\right)=(0.0001,1)$ are considered. As obvious from Table IV, the IHSA gives a better solution compared to GA, PSO and HSA. Additionally, standard deviation, required number of iterations and convergence time are also less in proposed method compared to other methods.

B. Test system 2: IEEE 30-bus network

To validate the effectiveness of the proposed method, its performance has to be evaluated on larger system. The distribution network of IEEE 30-bus system is shown in Fig. 4 that has been employed for this task. This network is supplied from three primary distribution transformers connected at buses $\mathrm{B}_{1}, \mathrm{~B}_{6}$ and $\mathrm{B}_{13}$. The system has a total of 38 DOCRs installed at each end of the lines. In this study, three DGs are assumed to be connected at buses $\mathrm{B}_{3}, \mathrm{~B}_{10}$ and $\mathrm{B}_{15}$ with the capacities of 10,5 and 10 MVA respectively.

TABLE VI. Results for IEEE 30-bus network

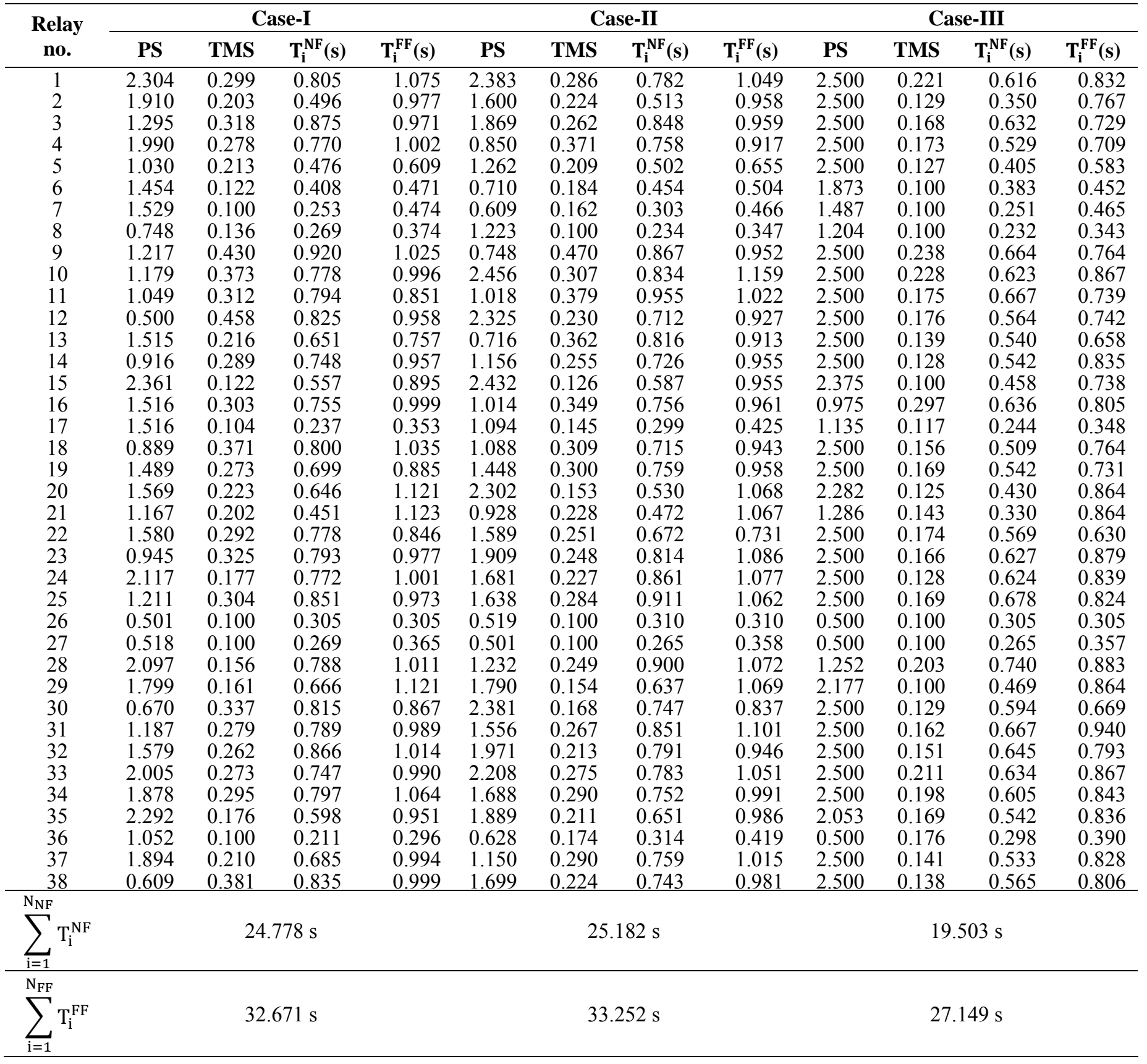

The selected DG technology is a synchronous type, operating nominally at 0.9 lagging power factor. The detail information about the system is given in $[18,31,33]$. The CT ratio for each relay is considered to be 200:1. The 3- $\Phi$ short-circuits results for near-end and far-end faults and P/B relay pairs are listed in Table V. 
The obtained results for Case-I, Case-II and Case-III are presented in Table VI, which include the relay settings and operating time of primary relays. The obtained CTI value for P/B relay pairs is presented in Table VII. As can be seen from Table VII, the CTI constraints for P/B relay pairs 10-28, 15-13, 21-23, 22-23, 24-25, 28-31, 29-30, 33-36, 35-38 and 36-16 are violated for far-end faults in Case-I. On the other hand, the entire coordination constraints for P/B relay pairs are satisfied as given in Case-II. However, the total operating times of primary relays for near-end and far-end fault are $0.404 \mathrm{~s}$ and $0.581 \mathrm{~s}$ higher in Case-II compared to Case-I as shown in Table VI. In Case-II, all coordination constraints of P/B relay pairs are maintained, but the operating times of primary relays are large. In this complex test system, the violation in coordination constraints in Case-I and total operating time of primary relays in Case-II are increased. On the other hand, the quality of the solution in terms of operating time and coordination of $\mathrm{P} / \mathrm{B}$ relay pairs has been achieved using proposed OF2 as shown in the results of Case-III. The obtained total operating time of primary relays for near-end and far-end faults are in order of $5.275 \mathrm{~s}$ and $5.522 \mathrm{~s}$ less than Case-I, whereas these are $5.679 \mathrm{~s}$ and $6.103 \mathrm{~s}$ less as compared to CaseII. Also, the entire coordination constraints are satisfied in Case-III as shown in Table VII.

TABLE VII. CTI of P/B relay pairs for IEEE 30-bus network

\begin{tabular}{|c|c|c|c|c|c|c|c|c|c|c|c|c|c|c|c|}
\hline \multirow{3}{*}{ PR } & \multirow{3}{*}{ BR } & \multicolumn{6}{|c|}{ CTI (s) } & \multirow{3}{*}{ PR } & \multirow{3}{*}{ BR } & \multicolumn{6}{|c|}{ CTI (s) } \\
\hline & & \multicolumn{2}{|c|}{ Case-I } & \multicolumn{2}{|c|}{ Case-II } & \multicolumn{2}{|c|}{ Case-III } & & & \multicolumn{2}{|c|}{ Case-I } & \multicolumn{2}{|c|}{ Case-II } & \multicolumn{2}{|c|}{ Case-III } \\
\hline & & NF & FF & NF & FF & NF & FF & & & NF & FF & NF & FF & NF & FF \\
\hline 1 & 21 & 0.319 & ----- & 0.285 & ----- & 0.248 & ----- & 19 & 15 & 0.200 & 2.778 & 0.201 & 3.382 & 0.200 & 2.346 \\
\hline 1 & 28 & 0.200 & 0.210 & 0.286 & 0.201 & 0.263 & 0.200 & 19 & 16 & 0.299 & 0.426 & 0.201 & 0.243 & 0.263 & 0.272 \\
\hline 1 & 29 & 0.316 & 0.428 & 0.287 & 0.381 & 0.248 & 0.427 & 19 & 17 & 0.301 & 2.249 & 0.204 & 0.859 & 0.263 & 0.838 \\
\hline 2 & 20 & 0.625 & ----- & 0.555 & ----- & 0.514 & ----- & 20 & 22 & 0.201 & 0.351 & 0.201 & 0.206 & 0.200 & 0.465 \\
\hline 2 & 28 & 0.509 & 0.365 & 0.554 & 0.327 & 0.529 & 0.293 & 21 & 3 & 0.519 & ----- & 0.487 & ----- & 0.399 & ----- \\
\hline 2 & 29 & 0.626 & 0.623 & 0.556 & 0.564 & 0.514 & 0.603 & 21 & 23 & 0.527 & -0.038 & 0.617 & 0.201 & 0.552 & 0.200 \\
\hline 3 & 1 & 0.200 & 0.262 & 0.201 & 0.247 & 0.200 & 0.231 & 22 & 2 & 0.201 & 0.588 & 0.287 & 0.607 & 0.200 & 0.629 \\
\hline 4 & 2 & 0.208 & 0.684 & 0.201 & 0.615 & 0.240 & 0.876 & 22 & 23 & 0.200 & 0.166 & 0.417 & 0.412 & 0.313 & 0.306 \\
\hline 4 & 3 & 0.200 & 0.325 & 0.201 & 0.493 & 0.200 & 0.461 & 23 & 24 & 0.208 & 0.264 & 0.263 & 0.201 & 0.211 & 0.200 \\
\hline 5 & 4 & 0.525 & 0.919 & 0.415 & 0.552 & 0.304 & 0.580 & 23 & 37 & 0.200 & 1.415 & 0.201 & 0.720 & 0.200 & 2.077 \\
\hline 5 & 37 & 0.518 & 1.193 & 0.513 & 0.874 & 0.423 & 1.267 & 24 & 25 & 0.201 & 0.172 & 0.201 & 0.247 & 0.200 & 0.269 \\
\hline 6 & 5 & 0.201 & 0.217 & 0.201 & 0.244 & 0.200 & 0.259 & 26 & 8 & 0.201 & ----- & 0.201 & ----- & 0.200 & ----- \\
\hline 7 & 6 & 0.217 & 0.299 & 0.200 & 0.235 & 0.200 & 0.363 & 27 & 7 & 0.205 & 0.500 & 0.201 & 0.289 & 0.200 & 0.478 \\
\hline 8 & 6 & 0.201 & 0.342 & 0.270 & 0.322 & 0.219 & 0.408 & 28 & 31 & 0.201 & 0.162 & 0.201 & 0.274 & 0.200 & 0.376 \\
\hline 9 & 20 & 0.201 & 0.453 & 0.201 & 0.650 & 0.200 & 0.526 & 29 & 30 & 0.201 & 0.046 & 0.200 & 0.561 & 0.200 & 0.485 \\
\hline 9 & 21 & 0.203 & 0.506 & 0.200 & 0.426 & 0.200 & 0.449 & 30 & 32 & 0.200 & 0.267 & 0.200 & 0.238 & 0.200 & 0.255 \\
\hline 9 & 29 & 0.201 & 1.358 & 0.202 & 1.306 & 0.200 & 1.731 & 31 & 33 & 0.201 & 0.344 & 0.201 & 0.341 & 0.200 & 0.282 \\
\hline 10 & 20 & 0.342 & 1.469 & 0.234 & 3.167 & 0.241 & 2.541 & 32 & 34 & 0.201 & 0.254 & 0.202 & 0.224 & 0.200 & 0.246 \\
\hline 10 & 21 & 0.345 & 1.820 & 0.233 & 1.015 & 0.241 & 1.609 & 33 & 35 & 0.201 & 2.962 & 0.200 & 1.860 & 0.200 & 1.922 \\
\hline 10 & 28 & 0.227 & -7.45 & 0.233 & 3.637 & 0.256 & 3.223 & 33 & 36 & 0.240 & -3.561 & 0.203 & 3.974 & 0.202 & 1.735 \\
\hline 11 & 10 & 0.201 & 0.219 & 0.204 & 0.261 & 0.200 & 0.222 & 34 & 16 & 0.201 & 0.342 & 0.208 & 0.279 & 0.200 & 0.217 \\
\hline 12 & 9 & 0.200 & 0.293 & 0.240 & 0.200 & 0.200 & 0.263 & 34 & 17 & 0.203 & 4.959 & 0.211 & 1.279 & 0.200 & 1.153 \\
\hline 13 & 11 & 0.201 & 0.228 & 0.207 & 0.268 & 0.200 & 0.274 & 34 & 38 & 0.201 & 0.291 & 0.229 & 0.731 & 0.200 & 1.021 \\
\hline 14 & 12 & 0.211 & 0.210 & 0.201 & 0.440 & 0.200 & 0.308 & 35 & 15 & 0.302 & 0.559 & 0.309 & 0.661 & 0.200 & 0.413 \\
\hline 15 & 13 & 0.200 & 0.177 & 0.326 & 0.206 & 0.200 & 0.345 & 35 & 17 & 0.403 & ----- & 0.312 & ----- & 0.263 & ----- \\
\hline 16 & 14 & 0.202 & 0.356 & 0.200 & 0.465 & 0.200 & 1.109 & 35 & 38 & 0.401 & 0.167 & 0.329 & 0.202 & 0.263 & 0.210 \\
\hline 16 & 36 & 0.231 & ----- & 0.230 & ----- & 0.200 & ----- & 36 & 15 & 0.689 & 1.592 & 0.646 & 1.671 & 0.444 & 1.177 \\
\hline 17 & 14 & 0.720 & 0.993 & 0.657 & 0.990 & 0.592 & 1.531 & 36 & 16 & 0.787 & 19.746 & 0.646 & 4.368 & 0.507 & 3.395 \\
\hline 17 & 35 & 0.710 & ----- & 0.684 & ----- & 0.590 & ----- & 36 & 38 & 0.788 & 0.915 & 0.667 & 0.956 & 0.507 & 0.905 \\
\hline 18 & 4 & 0.201 & 0.843 & 0.202 & 0.417 & 0.200 & 0.741 & 37 & 19 & 0.201 & 0.392 & 0.200 & 0.475 & 0.200 & 0.569 \\
\hline 18 & 24 & 0.201 & 0.498 & 0.362 & 0.580 & 0.330 & 0.636 & 38 & 18 & 0.201 & 0.379 & 0.201 & 0.311 & 0.200 & 0.527 \\
\hline
\end{tabular}

The performance comparison of the proposed method with GA, PSO and HSA are tabulated in Table VIII. In this case, GA parameters as $\mathrm{P}_{\mathrm{s}}=300, \mathrm{CR}=0.8, \mathrm{MR}=0.1$, PSO parameters as $\mathrm{N}=100,\left(\mathrm{C}_{1}, \mathrm{C}_{2}\right)=(2.1,2.0)$, $\left(\mathrm{w}_{\min }, \mathrm{w}_{\max }\right)=(0.2,1.0),\left(\mathrm{v}_{\min }, \mathrm{v}_{\max }\right)=(-0.45,0.45)$, HSA parameters as HMS $=40, \mathrm{HMCR}=0.85, \mathrm{PAR}=0.3$, $\mathrm{bw}=0.01$, IHSA parameters as $\mathrm{HMS}=15, \mathrm{HMCR}=0.99,\left(\mathrm{PAR}_{\min }, \mathrm{PAR}_{\max }\right)=(0.3,0.7)$ and $\left(\mathrm{bw}_{\min }, \mathrm{bw}_{\max }\right)=$ $(0.0001,1)$ are considered. As can be seen, in Table VIII, the IHSA gives best solution in the less iteration with minimum deviation compared to GA, PSO and HSA. 
TABLE VIII. Performance analysis for IEEE 30-bus network for 50 simulations

\begin{tabular}{|c|c|c|c|c|c|c|c|c|}
\hline \multirow[t]{2}{*}{ Cases } & \multirow[t]{2}{*}{ Algorithm } & \multicolumn{4}{|c|}{$\sum_{i=1}^{N_{N F}} T_{i}^{N F}$} & \multirow{2}{*}{$\begin{array}{c}\text { Violated } \\
\text { cases }\end{array}$} & \multirow{2}{*}{$\begin{array}{c}\text { Number } \\
\text { of } \\
\text { iterations }\end{array}$} & \multirow{2}{*}{$\begin{array}{c}\text { Mean } \\
\text { convergence } \\
\text { time (s) }\end{array}$} \\
\hline & & $\begin{array}{l}\text { Best } \\
\text { value }\end{array}$ & $\begin{array}{l}\text { Worst } \\
\text { value }\end{array}$ & $\begin{array}{l}\text { Mean } \\
\text { value }\end{array}$ & $\begin{array}{l}\text { Standard } \\
\text { deviation }\end{array}$ & & & \\
\hline \multirow{4}{*}{ Case-I } & GA & 32.15 & 36.16 & 33.91 & 1.57 & 12 & 812 & 245 \\
\hline & PSO & 27.39 & 30.77 & 28.48 & 1.26 & 10 & 658 & 220 \\
\hline & HSA & 25.36 & 27.49 & 26.23 & 0.93 & 10 & 580 & 200 \\
\hline & IHSA & 24.78 & 25.77 & 25.17 & 0.40 & 10 & 385 & 128 \\
\hline \multirow{4}{*}{ Case-II } & GA & 36.24 & 41.34 & 38.72 & 1.78 & 1 & 1045 & 345 \\
\hline & PSO & 30.89 & 34.89 & 32.72 & 1.39 & 0 & 890 & 298 \\
\hline & HSA & 27.80 & 30.78 & 29.19 & 1.02 & 0 & 780 & 266 \\
\hline & IHSA & 25.18 & 26.19 & 25.52 & 0.53 & 0 & 475 & 185 \\
\hline \multirow{4}{*}{ Case-II } & GA & 30.78 & 33.76 & 32.08 & 1.13 & 0 & 895 & 272 \\
\hline & PSO & 26.12 & 27.90 & 27.12 & 0.94 & 0 & 752 & 231 \\
\hline & HSA & 23.12 & 24.37 & 23.74 & 0.56 & 0 & 650 & 213 \\
\hline & IHSA & 19.50 & 20.13 & 19.78 & 0.27 & 0 & 388 & 156 \\
\hline
\end{tabular}

\section{CONCLUSION}

In this paper, the IHSA is successfully applied to solve coordination problem of DOCRs with three different cases on IEEE 14-bus and IEEE 30-bus systems. In Case-I, only near-end faults are considered in the formulation of the coordination problem. By examining obtained relay settings for the far-end faults, miscoordination in a few primary and backup relay pairs is observed. These violations in coordination constraints increase in large interconnected system as presented in IEEE 30-bus network. By including far-end faults in coordination problem in Case-II, all coordination constraints for near-end and far-end faults are satisfied. However, the obtained total operating time of primary relays for near-end as well as far-end faults are higher in Case-II compared to Case-I. To reduce the total operating times of primary relays and mis-coordinations, the coordination problem is formulated with a new objective function in Case-III. The results of Case-III exhibit that the considerable reduction in total operating time of primary relays for both near-end and far-end faults are obtained compared to Case-I and Case-II with satisfying entire coordination constraints. Moreover, the effectiveness of the proposed method is evaluated by comparison with GA, PSO and HSA. The comparative analysis reveals that considerable reduction in operating time of relays is achieved using IHA compared GA, PSO and HSA. The improved convergence rate and statistical inference indicate that the proposed method can give effectual solution for the relay coordination problem.

\section{REFERENCES}

[1] A. S. Noghabi, J. Sadeh, and H. R. Mashhadi, "Considering different network topologies in optimal overcurrent relay coordination using a hybrid GA," IEEE Transactions on Power Delivery, vol. 24, no. 4, pp. 1857-1863, 2009.

[2] F. A. Albasri, A. R. Alroomi, and J. H. Talaq, "Optimal coordination of directional overcurrent relays using biogeography-based optimization algorithms," IEEE Transactions on Power Delivery, vol. 30, no. 4, pp. 1810-1820, 2015.

[3] B. Chattopadhyay, M. Sachdev, and T. Sidhu, "An on-line relay coordination algorithm for adaptive protection using linear programming technique," IEEE Transactions on Power Delivery, vol. 11, no. 1, pp. 165-173, 1996.

[4] A. J. Urdaneta, R. Nadira, and L. Perez Jimenez, "Optimal coordination of directional overcurrent relays in interconnected power systems," IEEE Transactions on Power Delivery, vol. 3, no. 3, pp. 903-911, 1988.

[5] A. J. Urdaneta, H. Restrepo, S. Marquez et al., "Coordination of directional overcurrent relay timing using linear programming," IEEE Transactions on Power Delivery, vol. 11, no. 1, pp. 122-129, 1996.

[6] D. Birla, R. P. Maheshwari, and H. Gupta, "A new nonlinear directional overcurrent relay coordination technique, and banes and boons of near-end faults based approach," IEEE Transactions on Power Delivery, vol. 21, no. 3, pp. 1176-1182, 2006.

[7] D. Birla, R. P. Maheshwari, and H. Gupta, "An approach to tackle the threat of sympathy trips in directional overcurrent relay coordination," IEEE Transactions on Power Delivery, vol. 22, no. 2, pp. 851-858, 2007.

[8] F. Razavi, H. A. Abyaneh, M. Al-Dabbagh et al., "A new comprehensive genetic algorithm method for optimal overcurrent relays coordination,” Electric Power Systems Research, vol. 78, no. 4, pp. 713-720, 2008.

[9] M. Thakur, and A. Kumar, "Optimal coordination of directional over current relays using a modified real coded genetic algorithm: A comparative study," International Journal of Electrical Power \& Energy Systems, vol. 82, pp. 484-495, 2016.

[10] M. M. Mansour, S. F. Mekhamer, and N.-S. El-Kharbawe, "A modified particle swarm optimizer for the coordination of directional overcurrent relays," IEEE Transactions on Power Delivery, vol. 22, no. 3, pp. 1400-1410, 2007.

[11] H. Zeineldin, E. El-Saadany, and M. Salama, "Optimal coordination of overcurrent relays using a modified particle swarm optimization," Electric Power Systems Research, vol. 76, no. 11, pp. 988-995, 2006.

[12] T. Amraee, "Coordination of directional overcurrent relays using seeker algorithm," IEEE Transactions on Power Delivery, vol. 27, no. 3, pp. 1415-1422, 2012.

[13] M. Alipour, S. Teimourzadeh, and H. Seyedi, "Improved group search optimization algorithm for coordination of directional overcurrent relays," Swarm and Evolutionary Computation, vol. 23, pp. 40-49, 2015. 
[14] S. S. Gokhale, and V. S. Kale, "An application of a tent map initiated chaotic firefly algorithm for optimal overcurrent relay coordination,” International Journal of Electrical Power \& Energy Systems, vol. 78, pp. 336-342, 2016.

[15] A. M. Othman, and A. Y. Abdelaziz, "Enhanced Backtracking Search Algorithm for Optimal Coordination of Directional Over-current Relays Including Distributed Generation," Electric Power Components and Systems, vol. 44, no. 3, pp. 278-290, 2016.

[16] M. Y. Shih, C. A. C. Salazar, and A. C. Enríquez, "Adaptive directional overcurrent relay coordination using ant colony optimisation," IET Generation, Transmission \& Distribution, vol. 9, no. 14, pp. 2040-2049, 2015.

[17] A. A. Kalage, and N. D. Ghawghawe, "Optimum Coordination of Directional Overcurrent Relays Using Modified Adaptive Teaching Learning Based Optimization Algorithm,” Intelligent Industrial Systems, vol. 2, no. 1, pp. 55-71, 2016.

[18] M. N. Alam, B. Das, and V. Pant, "A comparative study of metaheuristic optimization approaches for directional overcurrent relays coordination," Electric Power Systems Research, vol. 128, pp. 39-52, 2015.

[19] P. P. Bedekar, and S. R. Bhide, "Optimum coordination of directional overcurrent relays using the hybrid GA-NLP approach," IEEE Transactions on Power Delivery, vol. 26, no. 1, pp. 109-119, 2011.

[20] J. Radosavljevi, x, M. Jevti et al., "Hybrid GSA-SQP algorithm for optimal coordination of directional overcurrent relays," IET Generation, Transmission \& Distribution, vol. 10, no. 8, pp. 1928-1937, 2016.

[21] A. Srivastava, J. M. Tripathi, S. R. Mohanty et al., "Optimal over-current relay coordination with distributed generation using hybrid particle swarm optimization-gravitational search algorithm," Electric Power Components and Systems, vol. 44, no. 5, pp. 506-517, 2016.

[22] Z. W. Geem, J. H. Kim, and G. Loganathan, “A new heuristic optimization algorithm: harmony search,” Simulation, vol. 76, no. 2, pp. 60-68, 2001.

[23] K. S. Lee, and Z. W. Geem, "A new meta-heuristic algorithm for continuous engineering optimization: harmony search theory and practice," Computer Methods in Applied Mechanics and Engineering, vol. 194, no. 36, pp. 3902-3933, 2005.

[24] J. Chen, Q.-k. Pan, and J.-q. Li, "Harmony search algorithm with dynamic control parameters," Applied Mathematics and Computation, vol. 219, no. 2, pp. 592-604, 2012.

[25] M. Mahdavi, M. Fesanghary, and E. Damangir, "An improved harmony search algorithm for solving optimization problems," Applied Mathematics and Computation, vol. 188, no. 2, pp. 1567-1579, 2007.

[26] L. d. S. Coelho, and V. C. Mariani, "An improved harmony search algorithm for power economic load dispatch," Energy Conversion and Management, vol. 50, no. 10, pp. 2522-2526, 2009.

[27] S. O. Degertekin, "Improved harmony search algorithms for sizing optimization of truss structures," Computers \& Structures, vol. 92 93, pp. 229-241, 2012.

[28] L. d. Santos Coelho, and D. L. de Andrade Bernert, "An improved harmony search algorithm for synchronization of discrete-time chaotic systems," Chaos Solitons Fractals, vol. 41, no. 5, pp. 2526-2532, 2009.

[29] W. Sun, and X. Chang, "An improved harmony search algorithm for power distribution network planning," Journal of Electrical and Computer Engineering, vol. 2015, 2015

[30] M. N. Alam, B. Das, and V. Pant, "An interior point method based protection coordination scheme for directional overcurrent relays in meshed networks," International Journal of Electrical Power \& Energy Systems, vol. 81, pp. 153-164, 2016.

[31] R. Christie, "Power Systems Test Case Archive" [Online]. Available: http://www. ee. washington. edu/research/pstca/.

[32] K. A. Saleh, H. H. Zeineldin, A. Al-Hinai et al., "Optimal Coordination of Directional Overcurrent Relays Using a New Time-CurrentVoltage Characteristic," IEEE Transactions on Power Delivery, vol. 30, no. 2, pp. 537-544, 2015.

[33] R. Chabanloo, H. A. Abyaneh, A. Agheli et al., "Overcurrent relays coordination considering transient behaviour of fault current limiter and distributed generation in distribution power network," IET Generation, Transmission \& Distribution, vol. 5, no. 9, pp. 903911, 2011. 